\title{
Decoration of Vertically Aligned Carbon Nanotubes with Semiconductor Nanoparticles Using Atomic Layer Deposition
}

Anna Szabó ${ }^{1}$, László Péter Bakos ${ }^{2}$, Dániel Karajz ${ }^{2}$, Tamás Gyulavári ${ }^{1}$, Zsejke-Réka Tóth ${ }^{1,3}$, Zsolt Pap ${ }^{3,4}{ }^{\oplus}$, Imre Miklós Szilágyi ${ }^{2}$, Tamás Igricz ${ }^{5}$, Bence Parditka ${ }^{6}$, Zoltán Erdélyi ${ }^{6}$ and Klara Hernadi ${ }^{1, * \mathbb{D}}$

1 Department of Applied and Environmental Chemistry, University of Szeged, H-6720 Szeged, Hungary; szabo.anna@chem.u-szeged.hu (A.S.); gyulavarit@chem.u-szeged.hu (T.G.); tothzsejkereka@chem.u-szeged.hu (Z.-R.T.)

2 Department of Inorganic and Analytical Chemistry, Budapest University of Technology and Economics, Muegyetem rakpart 3., H-1111 Budapest, Hungary; laszlobakos@hotmail.com (L.P.B.); karda412@gmail.com (D.K.); imre.szilagyi@mail.bme.hu (I.M.S.)

3 Nanostructured Materials and Bio-Nano-Interfaces Center, Interdisciplinary Research Institute on Bio-Nano-Sciences, Babeș-Bolyai University, Treboniu Laurian Str. 42, RO-400271 Cluj-Napoca, Romania; pzsolt@chem.u-szeged.hu

4 Institute of Environmental Science and Technology, University of Szeged, Tisza Lajos krt. 103, H-6725 Szeged, Hungary

5 Department of Organic Chemistry and Technology, Budapest University of Technology and Economics, Budafoki út 8. F. II Building, H-1111 Budapest, Hungary; igricz.tamas@gmail.com

6 Department of Solid State Physics, Faculty of Sciences and Technology, University of Debrecen, P.O. Box 400, H-4002 Debrecen, Hungary; parditka.bence@science.unideb.hu (B.P.); zoltan.erdelyi@science.unideb.hu (Z.E.)

* Correspondence: hernadi@chem.u-szeged.hu; Tel.: +36-62-544626

Received: 5 March 2019; Accepted: 27 March 2019; Published: 2 April 2019

\begin{abstract}
Vertically aligned carbon nanotubes (VACNTs or "CNT forest") were decorated with semiconductor particles $\left(\mathrm{TiO}_{2}\right.$ and $\left.\mathrm{ZnO}\right)$ by atomic layer deposition (ALD). Both the structure and morphology of the components were systematically studied using scanning (SEM) and high resolution transmission electron microscopy (HRTEM), energy-dispersive X-ray spectroscopy (EDX), Raman spectroscopy, and X-ray diffraction (XRD) methods. Characterization results revealed that the decoration was successful in the whole bulk of VACNTs. The effect of a follow-up heat treatment was also investigated and its effect on the structure was proved. It was attested that atomic layer deposition is a suitable technique for the fabrication of semiconductor/vertically aligned carbon nanotubes composites. Regarding their technological importance, we hope that semiconductor/CNT forest nanocomposites find potential application in the near future.
\end{abstract}

Keywords: vertically aligned carbon nanotubes; atomic layer deposition; semiconductor particles; semiconductor/CNT forest nanocomposites

\section{Introduction}

The vertically aligned carbon nanotube (VACNT), a sub-branch of the carbon nanotube family, is a relevant nanotechnology research topic nowadays. Its structure was synthetized by Li et al. for the first time in 1996 [1]. The VACNT are often called carbon nanotube forests in the literature and usually synthetized by applying the catalytic chemical vapor deposition (CCVD) technique [2]. The carbon nanotube forests differ from carbon nanotubes only in terms of orderliness, and CNT 
forests are fixed to a (conductive) substrate [3-6] which might result in direct electrical connection. The carbon nanotube forests are often used in electrical devices due to their electrical conducting properties and can be found in microelectromechanical devices [7] such as gas sensors [8], but can also be used in the preparation of nanocomposite systems [9], and have been extensively used for field emission applications, as well $[10,11]$. In the literature, several methods are already published for the preparation of $\mathrm{ZnO}$ [12] and $\mathrm{TiO}_{2}$ [13] composites, such as electrochemical [14], sputtering [15], and atomic laser deposition (ALD) [16]. However, in the case of the above-mentioned structure (VACNT), principally, the composite formed only on the outer surface of the CNT forests, while inner carbon nanotubes remained bare without any coverage. Only a few publications can be found where real composites were formed which are homogeneously composed of vertically aligned carbon nanotubes covered by inorganic layer [12,13,16-18]. Due to the potential technological importance of semiconductor/CNT forest composites, there is demand to develop an effective synthesis process for its production. Composite materials are often used such as electron emitters [19], nanotransistors [20], electrochemiluminescence [21], and sensors [22].

Atomic layer deposition (ALD) is a convenient chemical coating method for nanostructures. A wide range of materials can be deposited layer after layer, which enables the control of the thickness on the nanometer scale $[23,24]$. ALD was already used to deposit different metal oxides on single and multi-walled carbon nanotubes, such as $\mathrm{TiO}_{2}, \mathrm{ZnO}, \mathrm{ZrO}_{2}$, and $\mathrm{Fe}_{2} \mathrm{O}_{3}$. These composites were tested in many applications, e.g., as transistors, photodetectors, electrodes or in photocatalysis [12,13,25-28].

The addition of carbon nanotubes to various semiconductors seems to be a suitable solution for the elongation of the lifetime of photogenerated $\mathrm{e}^{-} / \mathrm{h}^{+}$pairs, thus preventing their recombination [29]. The effect of other carbonaceous materials were also investigated [30], and found that carbon nanotubes (CNTs) proved to have the best electron sink capabilities making it suitable to store and transport photogenerated electrons of semiconductor materials [31]. Applying various fabrication methods, many different types of metal oxides, such as $\mathrm{TiO}_{2}$ [32,33], $\mathrm{SnO}_{2}$ [34], $\mathrm{Cu}_{2} \mathrm{O}$ [35], $\mathrm{CeO}_{2}$ [36] and $\mathrm{ZnO}$ [37-39] were already deposited onto the surface of multi-walled carbon nanotubes (MWCNTs). Due to their outstanding electrical properties, large surface area, hollow structure, and adsorption sites, carbon nanotubes are approved components in nanocomposites which proved to be effective and very sensitive gas sensors [40,41].

Since 1972, the most investigated semiconductor has been titanium dioxide [42], especially its anatase phase. This material can be considered as an ideal photocatalytic candidate [43] with its band-gap (3.1-3.2 eV $\approx \lambda=387-400 \mathrm{~nm}$ ) being quite close to the visible light absorption range. Its absorption overlap with the sunshine radiation at the surface of Earth enabling the possibility to utilize sunlight [43]. Titanium dioxide is inexpensive and non-toxic, moreover, it is available in large amounts. Its exceptional properties combined with MWCNT offer promising materials for potential applications.

Due to its outstanding performance in electronics, optics, and photonics systems, $\mathrm{ZnO}$ also has widespread attention in the literature [44]. It is also applied as photocatalyst under UV irradiation (its band gap is $3.37 \mathrm{eV}$ ) for the degradation of various organic contaminants [40,45]. Among other semiconductor oxides, the utilization of $\mathrm{ZnO}$ as photocatalyst is favorable because of its relatively large quantum efficiency [46] and also its large exciton binding energy $(60 \mathrm{meV})$ [47].

The CNT has beneficial properties, such as a large surface area, excellent electrical conductivity and a high capacity for electron reservoirs. Therefore, significant achievements have already been published regarding the improvement of the photocatalytic efficiency of ZnO/CNT [48] and $\mathrm{TiO}_{2} / \mathrm{CNT}$ [49] composites and to understand the mechanisms of enhancing the photocatalytic performance. Due to their prominent properties, these composites are often used in gas sensors, too, for e.g., $\mathrm{TiO}_{2} / \mathrm{CNT}$ for the detection of $\mathrm{H}_{2}$ [50] or $\mathrm{ZnO} / \mathrm{CNT}$ for the detection of $\mathrm{NH}_{3}$ [51]. Many studies have been published in the literature regarding the synthesis methods of $\mathrm{ZnO}$, including wet chemical-based methods [52], plasma-assisted sputtering [53], and microwave irradiation [54], while for $\mathrm{TiO}_{2}$ preparation usually sol-gel [55] and hydrothermal methods [49] are applied. 
Summarizing the literature data for CNT forest nanocomposites, it can be concluded that the deposition of semiconductor materials into the intertubular region of CNT forests is rather challenging. Supposedly, due to poor wettability of the CNT surface, regular impregnation techniques are generally miscarried. In consequence, the aim of this work was to apply atomic layer deposition for the fabrication semiconductor/CNT forest nanocomposites using either Ti or Zn precursor.

\section{Materials and Methods}

\subsection{Materials}

During the experiments the following materials were used: Aluminum plates (WRS Materials Company, San Jose, CA, USA), cobalt (cobalt(II)-nitrate hexahydrate, 99\% (Sigma-Aldrich, Saint Louis, MO, USA), iron (iron(III)-nitrate nonahydrate, 99.9\% (Sigma-Aldrich, Saint Louis, MO, USA) precursors and absolute ethanol (VWR) were used in the formation of the catalyst layer. For the CCVD synthesis ethylene (purity > 99.9\%), hydrogen (purity 99.5\%), and nitrogen (purity 99.995\%) gases were applied, which were supplied by the company of Messer Hungary (Szeged, Hungary). The precursors used during the atomic layer deposition were $\mathrm{TiCl}_{4}$ and $\mathrm{Zn}\left(\mathrm{C}_{2} \mathrm{H}_{5}\right)_{2}$ from Sigma-Aldrich.

\subsection{Catalyst Preparation}

First, iron and cobalt salts $\left(0.888 \mathrm{~g} \mathrm{Fe}\left(\mathrm{NO}_{3}\right)_{3} \cdot 9 \mathrm{H}_{2} \mathrm{O}\right.$ and $\left.0.855 \mathrm{~g} \mathrm{Co}\left(\mathrm{NO}_{3}\right)_{2} \cdot 6 \mathrm{H}_{2} \mathrm{O}\right)$ were dissolved in $50 \mathrm{~cm}^{3}$ of absolute ethanol with the catalyst ratio of 2:3 and this catalyst ink had a transition metal concentration of $0.11 \mathrm{M}$. The effect of aging was avoided, the solution was prepared freshly before the dip-coating method.

In the following step, the catalyst layer on aluminum sheet was prepared by applying the dip-coating technique. Before this, the substrate was washed with distilled water, ethanol, and acetone in order to remove all contaminations (motes, grease spots, etc.), then the sheet was cut into $3 \times 2.5 \mathrm{~cm}$ sized pieces. Thereafter, the clean substrate was heat treated for $1 \mathrm{~h}$ at $400{ }^{\circ} \mathrm{C}$ in a static oven, and in this way-according to our former results-a thicker native oxide layer formed on the aluminum sheet which promoted the production of CNT forests during CCVD synthesis [3].

Dip-coating is an easy and well-controllable method to form a catalyst layer on the substrate. The aluminum sheet was submerged in the catalyst ink for $10 \mathrm{~s}$, where the dipping and withdrawal speeds were $200 \mathrm{~mm} \times \mathrm{min}^{-1}$. The catalyst layer was built by KSV dip coater LM (KSV Instruments Ltd., Helsinki, Finland). The aluminum sheet with catalyst layer were heat treated again at $400{ }^{\circ} \mathrm{C}$ for $1 \mathrm{~h}$ in order to stabilize the catalyst on the surface of the substrate.

\subsection{CCVD Synthesis}

The CNT forests were prepared by the CCVD technique. The cut-to-size aluminum sheets were placed into a quartz boat and put in the pre-heated tube furnace at $640{ }^{\circ} \mathrm{C}$ (the aluminum melting point is $\left.660^{\circ} \mathrm{C}\right)$. The reaction time was $15 \mathrm{~min}$, and the carbon source was ethylene $\left(70 \mathrm{~cm}^{3} / \mathrm{min}\right)$, the carrier gas was nitrogen $\left(50 \mathrm{~cm}^{3} / \mathrm{min}\right)$, the reducing agent was hydrogen $\left(100 \mathrm{~cm}^{3} / \mathrm{min}\right)$, and the gas feed contained water vapor $\left(30 \mathrm{~cm}^{3} / \mathrm{min}\right)$ in every experiment.

During the first step of the CCVD synthesis, in the reactor, inert atmosphere was set by circulating nitrogen for $2 \mathrm{~min}$. As the next step, the hydrogen gas valve was opened for $5 \mathrm{~min}$, in order to reduce the catalyst particles. Thereafter, ethylene gas and water vapor were introduced into the system for $15 \mathrm{~min}$. At the end of synthesis all gas flows were closed except for the nitrogen. After rinsing the reactor, the quartz tube was taken out from the furnace. The system was cooled down to room temperature, then the as-prepared samples were removed from the reactor. The structure of as-prepared vertically aligned carbon nanotubes is shown in Figure 1, with an average height of CNT forest of $15.5 \mu \mathrm{m}$. A typical specific surface area value for multiwalled carbon nanotubes is approx. $180 \mathrm{~m}^{2} / \mathrm{g}$ [33]. The estimated surface of CNT to be coated was a few $\mathrm{cm}^{2}$. 


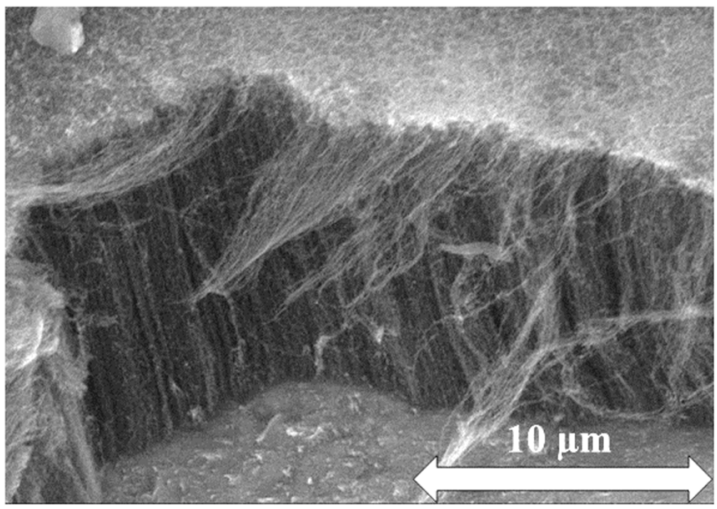

Figure 1. SEM image of as-prepared carbon nanotube forest.

\subsection{Atomic Layer Deposition}

Atomic layer deposition of the metal oxides was carried out at 1 mbar pressure in a Beneq TFS-200-186 ALD thermal reactor (Beneq, Espoo, Finland) equipped with a cross-flow reaction chamber with maximum reaction space diameter of $200 \mathrm{~mm}$ and height of $3 \mathrm{~mm}$ for fast film processing. $\mathrm{TiO}_{2}$ was deposited by the reaction of $\mathrm{TiCl}_{4}$ and $\mathrm{H}_{2} \mathrm{O}$ at $300{ }^{\circ} \mathrm{C}$, and $\mathrm{ZnO}$ layers were made with $\left(\mathrm{C}_{2} \mathrm{H}_{5}\right)_{2} \mathrm{Zn}$ and $\mathrm{H}_{2} \mathrm{O}$ at $200{ }^{\circ} \mathrm{C}$. For $\mathrm{TiO}_{2}, 400$ cycles were used, whereas for $\mathrm{ZnO}, 120$ were used; one cycle was composed of $0.3 \mathrm{~s}$ metal precursor pulse, $3 \mathrm{~s} \mathrm{~N} \mathrm{~N}_{2}$ purge, $0.3 \mathrm{~s} \mathrm{H}_{2} \mathrm{O}$ pulse and $3 \mathrm{~s} \mathrm{~N}_{2}$ purge. (Preliminary measurements revealed the sufficiency of even shorter pulse-purge periods; however longer cycles were applied for safety). The schematics of the ALD method are shown in Figure 2. Oxide layers were also grown on glass substrates under the same conditions and the theoretical thickness of the layers was measured by profilometer (AMBIOS XP-1, Crediton, UK); $40 \mathrm{~nm}$ for $\mathrm{TiO}_{2}$, and $20 \mathrm{~nm}$ for $\mathrm{ZnO}$. The growth speed for $\mathrm{TiO}_{2}$ and $\mathrm{ZnO}$ was found to be $0.1 \mathrm{~nm} /$ cycle and $0.17 \mathrm{~nm} /$ cycle, respectively. The non-uniformity of as-prepared layers was also investigated by profilometric measurements on glass substrates arranged evenly on the entire plate of the reaction chamber with a diameter of $200 \mathrm{~mm}$. Results revealed that non-uniformity on the entire plate was lower than $5 \%$ in the relevant thickness range. (Since our sample was much smaller than the plate, we can presume that non-uniformity is negligible in the current system.)

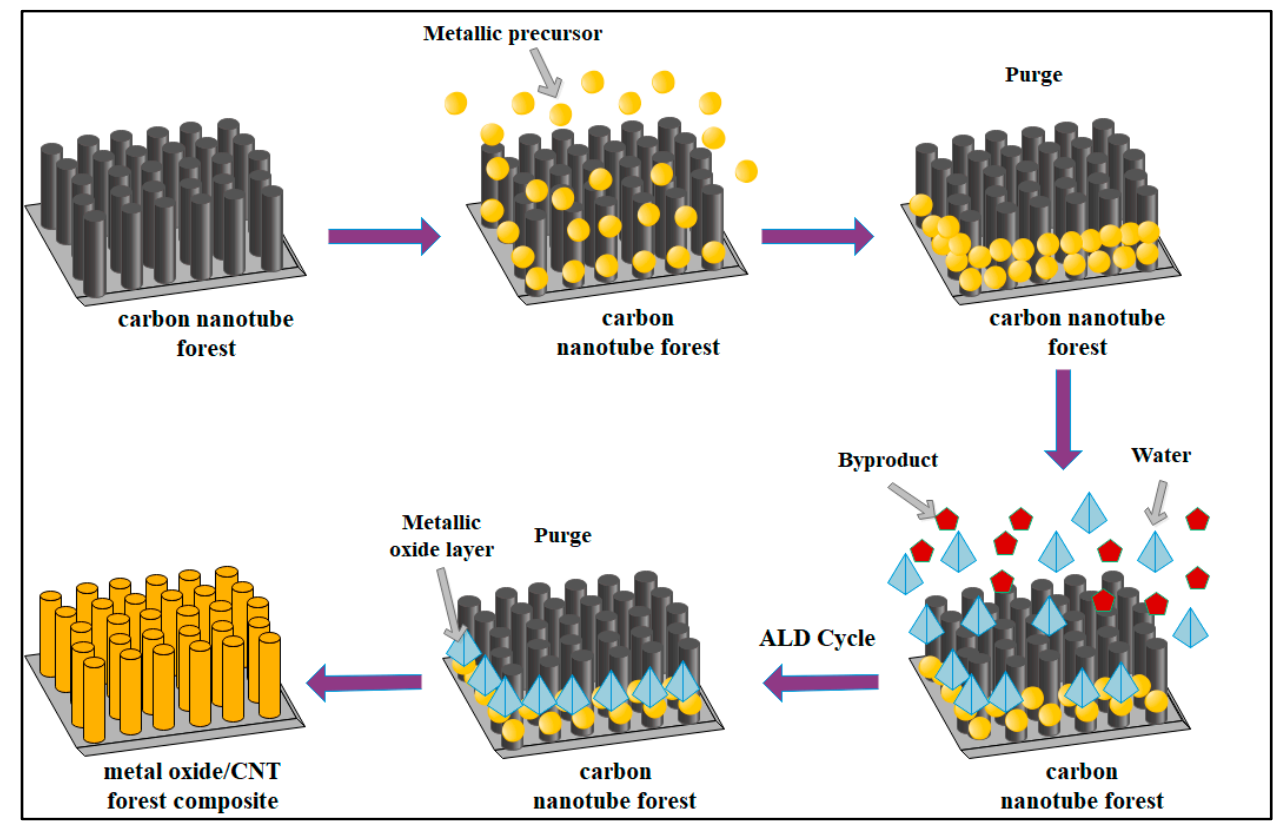

Figure 2. Schematic image of atomic layer deposition method. 


\subsection{Characterization of Samples}

Transmission electron microscopy (TEM) measurements were carried out using a FEI Tecnai G2 20 X-TWIN (200 keV) type instrument (FEI, Hillsboro, OR, USA), in order to test the quality of the carbon nanotubes. The samples were removed from the $\mathrm{Al}$ surface, then put into an Eppendorf vial and a small amount of the CNT was suspended in $1.25 \mathrm{~cm}^{3}$ absolute ethanol. In the next step, 2-3 droplets were dropped from this suspension onto the surface of a holey carbon grid (Lacey, CF 200, Electron Microscopy Sciences, Hatfield, USA. The TEM images were analyzed by using ImageJ software (Bethesda, MD, USA).

Scanning Electron Microscopy (SEM) analyses were performed with a Hitachi S-4700 Type II FE-SEM (5-15 keV) type instrument (Tokyo, Japan), in order to determine the orientation of the CNT forests. The samples were tilted at a $35^{\circ}$ angle in all cases to investigate the carbon nanotube forests from each side. SEM images were analyzed by using ImageJ software. The above-mentioned instrument was also used to perform the EDX analysis, complemented by a Röntec XFlash Detector 3001 detector (Bruker, Karlsruhe, Germany).

Raman spectra were recorded on a Jobin Yvon Labram Raman instrument with an Olympus BX41 microscope (Tokyo, Japan) using green Nd-YAG laser $(\lambda=532 \mathrm{~nm})$.

XRD patterns were recorded on a PANanalytical X'Pert Pro MPD X-ray diffractometer (Malvern Panalytical Ltd., Malvern, UK) using $\mathrm{Cu}$ K $\alpha$ radiation.

\section{Results}

For the fabrication of metal oxide/CNT forest composites, both $\mathrm{ZnO}$ and $\mathrm{TiO}_{2}$ were deposited onto the surface of carbon nanotubes using the ALD technique. Samples were thoroughly characterized right after deposition, then both $\mathrm{ZnO}$ and $\mathrm{TiO}_{2}$ coated carbon nanotube forests were heat-treated in order to observe the change in the crystal structure of the semiconductor oxides. During heat treatment, inert atmosphere was used because carbon nanotubes burn away in the presence of oxygen atmosphere at $400{ }^{\circ} \mathrm{C}$. The heat treatment was carried out in a tube furnace for $4 \mathrm{~h}$, at $400{ }^{\circ} \mathrm{C}$ in argon atmosphere.

\section{1. $\mathrm{ZnO}$ and $\mathrm{TiO}_{2}$ Coated Carbon Nanotube Forests}

\subsubsection{Scanning Electron Microscopy Observations}

SEM measurements revealed that the deposition of both metal oxides were successful. As can be seen in Figure 2, carbon nanotubes were decorated with nanosized particles in the whole bulk of the CNT forest. Analyzing the SEM images, it was found that the structure of the carbon nanotube forests was unmodified, and the $\mathrm{TiO}_{2}$ and $\mathrm{ZnO}$ were located on the carbon nanotube surface (Figure 3). As expected, no discernible changes were identified between the SEM images of the non-heat-treated and heat-treated samples. Therefore, the samples were investigated with EDX measurements too.

The average composition of the samples is shown in Table 1. While the pristine CNT forest was composed of nearly pure carbon, composite samples contained further elements. Besides the covering oxides $\left(\mathrm{TiO}_{2}\right.$ and $\left.\mathrm{ZnO}\right)$, traces of iron, cobalt and chlorine could be found in certain samples. The former two elements came from the catalyst of CNT growth, whilst, in the case of the $\mathrm{TiO}_{2} / \mathrm{CNT}$, the chlorine was the residue from the $\mathrm{TiCl}_{4}$ precursor used during ALD. The presence of the aluminum substrate was also observable in these data; however, values were eliminated for better comparability. According to EDX results, more $\mathrm{ZnO}$ was deposited than $\mathrm{TiO}_{2}$.

Interestingly, the relative amount of carbon compared to metal oxides (excluding aluminum support) became significantly lower after heat treatment, which may be due to the crystallization of $\mathrm{TiO}_{2}$. As was already mentioned, albeit the treatment was implemented under oxygen-free circumstances, a significant deficit of carbon was found compared to both $\mathrm{Zn}$ and Ti content. 


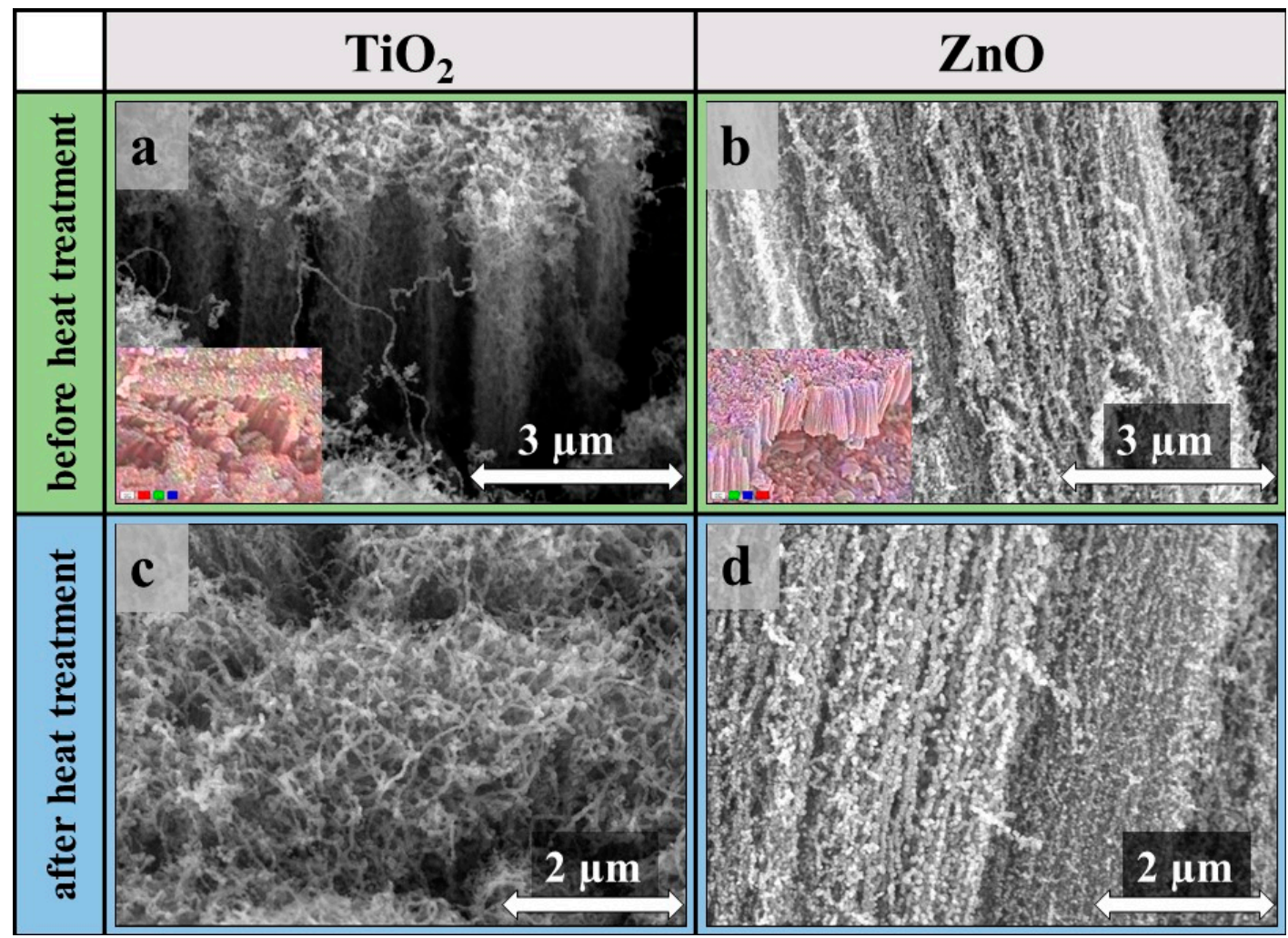

Figure 3. $\mathrm{SEM}$ images of $\mathrm{TiO}_{2}(\mathbf{a}, \mathbf{c})$ and $\mathrm{ZnO}(\mathbf{b}, \mathbf{d})$ coated $\mathrm{CNT}$ forests before $(\mathbf{a}, \mathbf{b})$ and after $(\mathbf{c}, \mathbf{d})$ heat treatment, element mapping of CNT forest composites (inset (a)-red: Ti, green: C, blue: O; inset (b)-red: Zn, green: $\mathrm{C}$, blue: $\mathrm{O})$.

Table 1. Composition of the samples from EDX spectra (b.HT: Before heat treatment; a.HT: After heat treatment).

\begin{tabular}{cccccccccccccccc}
\hline Sample & \multicolumn{10}{c}{ Atomic $\%$} \\
\hline & \multicolumn{1}{c}{ C } & \multicolumn{10}{c}{ O } & \multicolumn{10}{c}{ Fe } & \multicolumn{2}{c}{ Co } & Ti & Cl & Zn \\
\hline & b.HT & a.HT & b.HT & a.HT & b.HT & a.HT & b.HT & a.HT & b.HT & a.HT & b.HT & a.HT & b.HT & a.HT \\
\hline $\mathrm{CNT}$ & 97.7 & 97.7 & 2.3 & 2.3 & - & - & - & - & - & - & - & - & - & - \\
\hline $\mathrm{TiO}_{2} / \mathrm{CNT}$ & 51.3 & 23.1 & 35.5 & 61.6 & 0.1 & 0.0 & 0.1 & 0.0 & 12.9 & 13.8 & 0.1 & 1.5 & - & - \\
\hline $\mathrm{ZnO} / \mathrm{CNT}$ & 61.7 & 16.5 & 19.3 & 59.9 & 0.1 & 0.0 & 0.0 & 0.0 & - & - & - & - & 18.9 & 23.6 \\
\hline
\end{tabular}

\subsubsection{Raman Spectroscopy Results}

Raman spectroscopy measurements were carried out in order to determine the Raman shift as well as to investigate the effect of $\mathrm{TiO}_{2}$ and $\mathrm{ZnO}$ on the Raman spectra of CNT forest.

On the Raman spectra of each sample (Figure 4$)$, the D $\left(\sim 1340 \mathrm{~cm}^{-1}\right)$ and G bands $\left(\sim 1580 \mathrm{~cm}^{-1}\right)$ of the carbon are present, which come from the carbon nanotubes. The characteristic peaks of anatase can be seen on the spectrum of $\mathrm{TiO}_{2} / \mathrm{CNT}$ at 141, 400, 516 and $637 \mathrm{~cm}^{-1}$ [56]. In the case of $\mathrm{ZnO} / \mathrm{CNT}$, only two small peaks of the $\mathrm{ZnO}$ are visible, at 380 and $438 \mathrm{~cm}^{-1}$ [57] $\mathrm{I}_{\mathrm{D}} / \mathrm{I}_{\mathrm{G}}$ ratios of $\mathrm{D}$ and $\mathrm{G}$ peaks from carbon nanotubes were calculated to provide information on their graphitization (Table 2). The ratio of the $\mathrm{D}$ and $\mathrm{G}$ peaks intensities $\left(\mathrm{I}_{\mathrm{D}} / \mathrm{I}_{\mathrm{G}}\right)$ changed during the deposition of the metal oxides (Table 2) which makes the chemical bond probable between $\mathrm{Ti} / \mathrm{Zn}$ and CNT [58,59]. It was proved earlier that there is a strong correlation between the adherence of metal oxide particles to CNT surfaces and the density of defect sites in the carbon nanotube forest [60] Surprisingly, the heat-treated composite samples show lower $\mathrm{I}_{\mathrm{D}} / \mathrm{I}_{\mathrm{G}}$ ratios, thus fewer defect sites again. For example, in the case of $\mathrm{ZnO} / \mathrm{CNT}$ sample $\mathrm{I}_{\mathrm{D}} / \mathrm{I}_{\mathrm{G}}$ was 1.08 , an even better ratio than that of a pristine CNT forest and suggests only a few defect sites in the carbon nanotube. In spite of the presence of inert atmosphere during heat treatment, 
the oxygen in the sample could oxidize amorphous carbon and outer layers (which always contain more defects) of CNTs, resulting in increased graphitization values. This finding is in good agreement with observations done during the interpretation of EDX results.

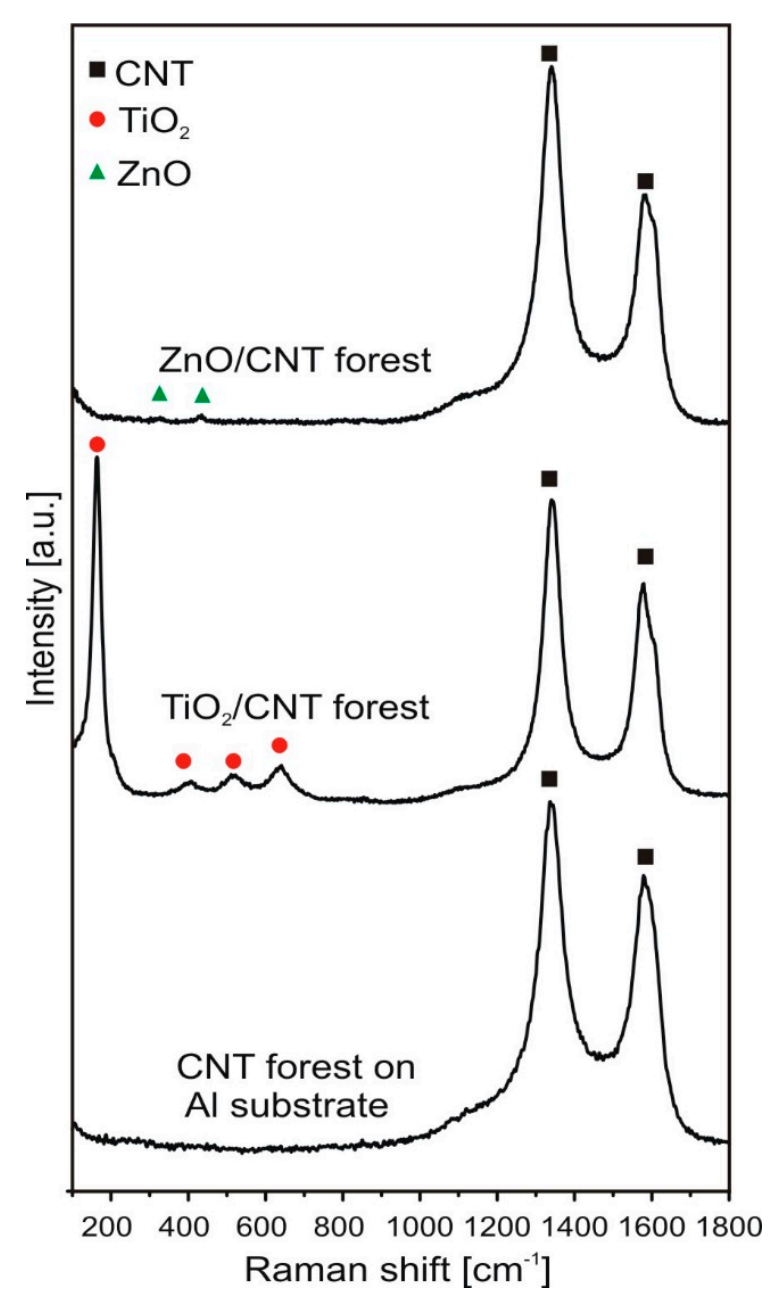

Figure 4. Raman spectra of the samples.

Table 2. $\mathrm{I}_{\mathrm{D}} / \mathrm{I}_{\mathrm{G}}$ ratios, $\mathrm{D}$ and $\mathrm{G}$ shifts of the samples (b.HT: Before heat treatment; a.HT: After heat treatment).

\begin{tabular}{ccccccc}
\hline Sample & \multicolumn{2}{c}{$\mathbf{I}_{\mathbf{D}} / \mathbf{I}_{\mathbf{G}}$} & \multicolumn{2}{c}{ D Shift $\left[\mathbf{c m}^{-\mathbf{1}}\right]$} & \multicolumn{2}{c}{ G Shift $\left[\mathbf{c m}^{-\mathbf{1}}\right]$} \\
\hline & b.HT & a.HT & b.HT & a.HT & b.HT & a.HT \\
\hline CNT & 1.26 & 1.26 & 1337.30 & 1337.30 & 1578.90 & 1578.90 \\
\hline $\mathrm{TiO}_{2} /$ CNT forest & 1.40 & 1.29 & 1341.69 & 1344.09 & 1578.90 & 1589.00 \\
\hline $\mathrm{ZnO} /$ CNT forest & 1.57 & 1.08 & 1343.15 & 1346.97 & 1589.15 & 1585.15 \\
\hline
\end{tabular}

\subsubsection{X-ray Diffraction Results}

In Figure 5, the diffraction peaks of $\mathrm{TiO}_{2}$ could not be observed during the investigation of $\mathrm{TiO}_{2} / \mathrm{CNT}$ forest, because it was present only in a small amount on the surface of carbon nanotubes (see also the EDX data). The $\mathrm{ZnO} / \mathrm{CNT}$ forest showed the peaks for the hexagonal $\mathrm{ZnO}$ (ICDD: 01-080-4199), and one peak (200) of the aluminum (ICDD: 00-004-0787) was present as well. A small diffraction peak is visible on the composites around $24^{\circ} 2 \theta$, which comes from the silicon sample holder. 


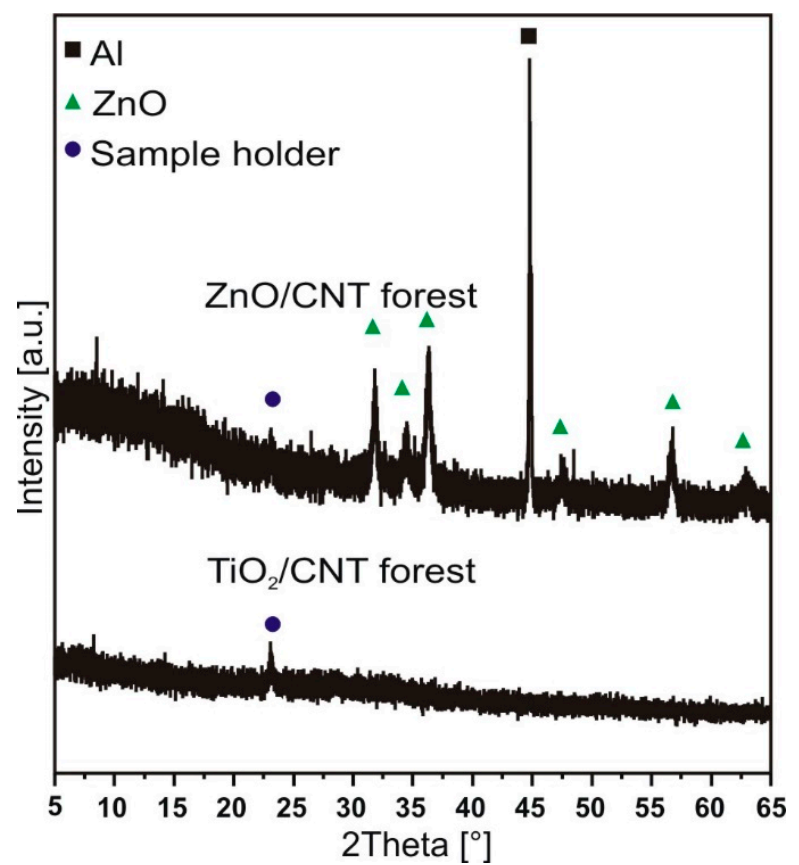

Figure 5. XRD diffractograms of the samples.

\subsubsection{Transmission Electron Microscopy Observations}

TEM measurements also confirmed that the metal oxides were successfully anchored onto the surface of carbon nanotubes composing forests. These measurements provided information about the quality of both carbon nanotubes and metal oxides as well.

From the TEM images (Figure 6) of composite samples, it can be concluded that the metal oxides truly enfold the surface of carbon nanotubes in both $\mathrm{TiO}_{2} / \mathrm{CNT}$ and $\mathrm{ZnO} / \mathrm{CNT}$ composites. HR-TEM images also revealed that the number of walls in carbon nanotubes were $4-5$ on average and their diameter varied between 5-6 nm, while the average diameters of the $\mathrm{TiO}_{2}$ and $\mathrm{ZnO}$ particles were $25 \mathrm{~nm}$ and $30 \mathrm{~nm}$, respectively.

In the case of $\mathrm{ZnO} / \mathrm{CNT}$ a more even coverage can be observed, compared to $\mathrm{TiO}_{2} / \mathrm{CNT}$ after heat treatment, but both metal oxides provided appreciable decoration on the CNT forest. From HR-TEM images, the interplanar lattice spacing was also calculated for metal oxides. It was observed that the lattice spacing did not change after heat treatment in both cases, thus no significant modification of crystal phases occurred. This value of $0.37 \mathrm{~nm}$ corresponds to the (001) facet of anatase in sample $\mathrm{TiO}_{2} / \mathrm{CNT}$. At first glance, this value seems to be changed in the case of $\mathrm{ZnO} / \mathrm{CNT}$. Before heat treatment the lattice spacing was found to be $0.28 \mathrm{~nm}$ for $\mathrm{ZnO}$, however, after heat treatment the lattice spacing was $0.32 \mathrm{~nm}$ based on HRTEM image. Literature data confirmed that both values belong to different facets ((0001) and (0110)) of a regular wurtzite hexagonal-structure $\mathrm{ZnO}$ particle [61,62]. It was also detected that the particles directly on the surface showed lower crystallinity compared to other quasi separated crystals. 


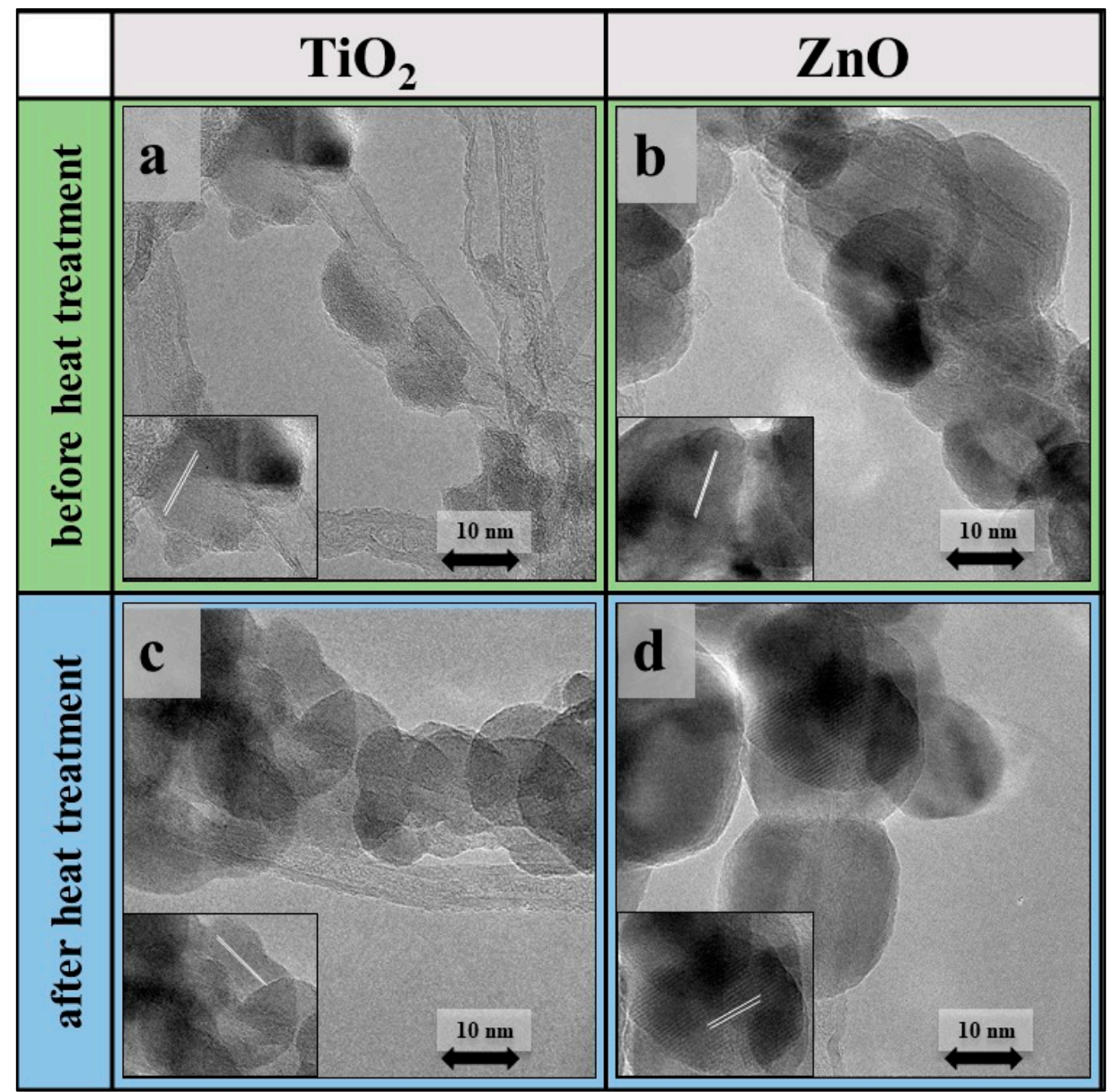

Figure 6. TEM images of $\mathrm{TiO}_{2}(\mathbf{a}, \mathbf{c})$ and $\mathrm{ZnO}(\mathbf{b}, \mathbf{d})$ coated CNT forests before $(\mathbf{a}, \mathbf{b})$ and after $(\mathbf{c}, \mathbf{d})$ heat treatment.

\section{Conclusions}

Surveying the relevant literature, it became obvious that the deposition of different materials into the interior region of CNT forests is a real challenge. Probably due to wettability problems, conventional impregnation techniques are generally unavailable for this purpose [63]. Therefore, in this work, we applied atomic layer deposition for the fabrication semiconductor/CNT forest nanocomposites using either Ti or Zn precursor. The resulting composite materials were characterized by various methods such as SEM, XRD, HRTEM, XRD, and Raman spectroscopy. Characterization results revealed that the decoration of $\mathrm{CNT}$ forest with both $\mathrm{Ti}_{2} \mathrm{O}$ and $\mathrm{ZnO}$ was successful in the whole bulk of VACNTs. Knowing the properties of applied semiconductors, a follow-up heat treatment was applied, and structural change was detected. Comparing the characterization results, it was found that treatment at $400{ }^{\circ} \mathrm{C}$ caused major alteration in the carbon nanotube but not in the semiconductor properties. Regarding the technological importance of these semiconductor/CNT forest nanocomposites, the authors hope that their work contributes to the application of these materials in the field of photocatalysis, supercapacitors or other applications soon.

Author Contributions: All the authors contributed to the discussion of the results and writing the manuscript. A.S. designed and performed the experiments, wrote the manuscript and contributed by taking the TEM images of CNT forests. L.P.B. and D.K. contributed by XRD and Raman measurements of CNT forests, wrote the manuscript. T.G. contributed by taking SEM images of CNT forests. Z.-R.T. contributed by Raman measurements of CNT forests. T.I., B.P. and Z.E. contributed to the ALD technic of the oxide layer. K.H., Z.P. and I.M.S. conceived and designed the experiments. 
Funding: This work was done by the help of financial support of the OTKA NN114463. An NRDI K 124212, an NRDI TNN_16 123631, a K 112644, a GINOP-2.3.2-15-2016-00041 and GINOP-2.2.1-15-2017-00084 grant are also acknowledged. The research within project No. VEKOP-2.3.2-16-2017-00013 was supported by the European Union and the State of Hungary, co-financed by the European Regional Development Fund. The research reported in this paper was supported by the Higher Education Excellence Program of the Ministry of Human Capacities in the frame of Nanotechnology and Materials Science research area of Budapest University of Technology (BME FIKP-NAT). I. M. Szilágyi thanks for a János Bolyai Research Fellowship of the Hungarian Academy of Sciences and an ÚNKP-18-4-BME-238 New National Excellence Program of the Ministry of Human Capacities, Hungary.

Conflicts of Interest: The authors declare no conflict of interest.

\section{References}

1. Li, W.Z.; Xie, S.S.; Qian, L.X.; Chang, B.H.; Zou, B.S.; Zhou, W.Y.; Zhao, R.A.; Wang, G. Large-Scale Synthesis of Aligned Carbon Nanotubes. Science 1996, 274, 1701-1703. [CrossRef] [PubMed]

2. Noda, S.; Hasegawa, K.; Sugime, H.; Kakehi, K.; Zhang, Z.; Maruyama, S.; Yamaguchi, Y. Millimeter-Thick Single-Walled Carbon Nanotube Forests: Hidden Role of Catalyst Support. Jpn. J. Appl. Phys. Part 2 Lett. 2007, 46, L399-L401. [CrossRef]

3. Szabó, A.; Kecsenovity, E.; Pápa, Z.; Gyulavári, T.; Németh, K.; Horvath, E.; Hernadi, K. Influence of synthesis parameters on CCVD growth of vertically aligned carbon nanotubes over aluminum substrate. Sci. Rep. 2017, 7, 1-11. [CrossRef]

4. Zhu, Z.G.; Garcia-Gancedo, L.; Chen, C.; Zhu, X.R.; Xie, H.Q.; Flewitt, A.J.; Milne, W.I. Enzyme-free glucose biosensor based on low density $\mathrm{CNT}$ forest grown directly on a $\mathrm{Si} / \mathrm{SiO}_{2}$ substrate. Sens. Actuators B Chem. 2013, 178, 586-592. [CrossRef]

5. Santhanagopalan, S.; Teng, F.; Meng, D.D. Ic-Compatible Deposition of Vertically-Aligned Cnt Forests for Micro-Supercapacitors. In Proceedings of the PowerMEMS, Washington, DC, USA, 1-4 December 2009.

6. Silva, T.A.; Zanin, H.; Saito, E.; Medeiros, R.A.; Vicentini, F.C.; Corat, E.J.; Fatibello-Filho, O. Electrochemical behaviour of vertically aligned carbon nanotubes and graphene oxide nanocomposite as electrode material. Electrochim. Acta 2014, 119, 114-119. [CrossRef]

7. Dahmardeh, M.; Vahdani Moghaddam, M.; Hian Tee, M.; Nojeh, A.; Takahata, K. The effects of three-dimensional shaping of vertically aligned carbon-nanotube contacts for micro-electro-mechanical switches. Appl. Phys. Lett. 2013, 103, 231606. [CrossRef]

8. Mudimela, P.R.; Scardamaglia, M.; González-León, O.; Reckinger, N.; Snyders, R.; Llobet, E.; Bittencourt, C.; Colomer, J.F. Gas sensing with gold-decorated vertically aligned carbon nanotubes. Beilstein J. Nanotechnol. 2014, 5, 910-918. [CrossRef]

9. Souier, T.; Santos, S.; Al Ghaferi, A.; Stefancich, M.; Chiesa, M. Enhanced electrical properties of vertically aligned carbon nanotube-epoxy nanocomposites with high packing density. Nanoscale Res. Lett. 2012, 7, 1-8. [CrossRef]

10. Di Bartolomeo, A.; Scarfato, A.; Giubileo, F.; Bobba, F.; Biasiucci, M. A local field emission study of partially aligned carbon-nanotubes by atomic force microscope probe. Carbon N. Y. 2007, 45, 2957-2971. [CrossRef]

11. Giubileo, F.; Di Bartolomeo, A.; Scarfato, A.; Iemmo, L.; Bobba, F.; Allende, S.; Sa, B. Local probing of the field emission stability of vertically aligned multi-walled carbon nanotubes. Carbon N. Y. 2008, 47, 1074-1080. [CrossRef]

12. Okeil, S.; Krausmann, J.; Dönges, I.; Pfleger, S.; Engstler, J.; Schneider, J.J. ZnS/ZnO@CNT and ZnS@CNT nanocomposites by gas phase conversion of ZnO@CNT. A systematic study of their photocatalytic properties. Dalt. Trans. 2017, 46, 5189-5201. [CrossRef] [PubMed]

13. Fisher, R.A.; Watt, M.R.; Konjeti, R.; Ready, W.J. Atomic Layer Deposition of Titanium Oxide for Pseudocapacitive Functionalization of Vertically-Aligned Carbon Nanotube Supercapacitor Electrodes. ECS J. Solid State Sci. Technol. 2015, 4, M1-M5. [CrossRef]

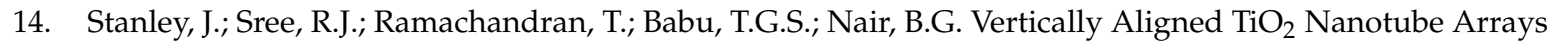
Decorated with $\mathrm{CuO}$ Mesoclusters for the Nonenzymatic Sensing of Glucose. J. Nanosci. Nanotechnol. 2017, 17, 2732-2739. [CrossRef]

15. Ouldhamadouche, N.; Achour, A.; Lucio-Porto, R.; Islam, M.; Solaymani, S.; Arman, A.; Ahmadpourian, A.; Achour, H.; Le Brizoual, L.; Djouadi, M.A.; et al. Electrodes based on nano-tree-like vanadium nitride and carbon nanotubes for micro-supercapacitors. J. Mater. Sci. Technol. 2018, 34, 976-982. [CrossRef] 
16. Warren, R.; Sammoura, F.; Tounsi, F.; Sanghadasa, M.; Lin, L. Highly active ruthenium oxide coating via ALD and electrochemical activation in supercapacitor applications. J. Mater. Chem. A 2015, 3, 15568-15575. [CrossRef]

17. Silva, R.M.; Ferro, M.C.; Araujo, J.R.; Achete, C.A.; Clavel, G.; Silva, R.F.; Pinna, N. Nucleation, growth mechanism, and controlled coating of ZnO ALD onto vertically aligned N-Doped CNTs. Langmuir 2016, 32, 7038-7044. [CrossRef]

18. Acauan, L.; Dias, A.C.; Pereira, M.B.; Horowitz, F.; Bergmann, C.P. Influence of Different Defects in Vertically Aligned Carbon Nanotubes on $\mathrm{TiO}_{2}$ Nanoparticle Formation through Atomic Layer Deposition. ACS Appl. Mater. Interfaces 2016, 8, 16444-16450. [CrossRef]

19. Jo, S.H.; Banerjee, D.; Ren, Z.F.; Jo, S.H.; Banerjee, D.; Ren, Z.F. Field emission of zinc oxide nanowires grown on carbon cloth Field emission of zinc oxide nanowires grown on carbon cloth. Appl. Phys. Lett. 2010, 1407, 1407-1409.

20. Goldberger, J.; Sirbuly, D.J.; Law, M.; Yang, P. ZnO Nanowire Transistors. J. Phys. Chem. B 2005, 109, 9-14. [CrossRef]

21. Zhang, R.; Fan, L.; Yang, S. Electrochemical route to the preparation of highly dispersed composites of $\mathrm{ZnO} /$ carbon nanotubes with significantly enhanced electrochemiluminescence from ZnO. J. Mater. Chem. 2008, 18, 4964-4970. [CrossRef]

22. Li, Q.H.; Liang, Y.X.; Wan, Q.; Wang, T.H. Oxygen sensing characteristics of individual ZnO nanowire transistors. Appl. Phys. Lett. 2004, 85, 6389. [CrossRef]

23. Johnson, R.W.; Hultqvist, A.; Bent, S.F. A brief review of atomic layer deposition: From fundamentals to applications. Mater. Today 2014, 17, 236-246. [CrossRef]

24. Szilágyi, I.M.; Nagy, D. Review on one-dimensional nanostructures prepared by electrospinning and atomic layer deposition. J. Phys. Conf. Ser. 2014, 559, 012010. [CrossRef]

25. Marichy, C.; Pinna, N. Carbon-nanostructures coated/decorated by atomic layer deposition: Growth and applications. Coord. Chem. Rev. 2013, 257, 3232-3253. [CrossRef]

26. Javey, A.; Kim, H.; Brink, M.; Wang, Q.; Ural, A.; Guo, J.; Mcintyre, P.; Mceuen, P.; Lundstrom, M.; Dai, H. High-k dielectrics for advanced carbon-nanotube transistors and logic gates. Nat. Mater. 2002, 1, 241-246. [CrossRef]

27. Lin, Y.-H.; Lee, P.-S.; Hsueh, Y.-C.; Pan, K.-Y.; Kei, C.-C.; Chan, M.-H.; Wu, J.-M.; Perng, T.-P.; Shih, H.C. Atomic Layer Deposition of Zinc Oxide on Multiwalled Carbon Nanotubes for UV Photodetector Applications. J. Electrochem. Soc. 2011, 158, K24-K27. [CrossRef]

28. Meng, X.; Ionescu, M.; Banis, M.N.; Zhong, Y.; Liu, H.; Zhang, Y.; Sun, S.; Li, R.; Sun, X. Heterostructural coaxial nanotubes of $\mathrm{CNT} @ \mathrm{Fe}_{2} \mathrm{O}_{3}$ via atomic layer deposition: Effects of surface functionalization and nitrogen-doping. J. Nanopar. Res. 2011, 13, 1207-1218. [CrossRef]

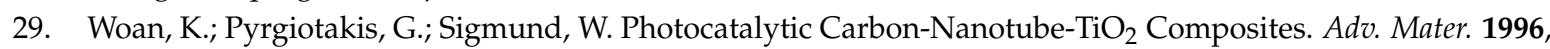
21, 2233-2239. [CrossRef]

30. Leary, R.; Westwood, A. Carbonaceous nanomaterials for the enhancement of $\mathrm{TiO}_{2}$ photocatalysis. Carbon N. Y. 2011, 49, 741-772. [CrossRef]

31. Portela, R.; Hernández-Alonso, M.D. Environmental applications of photocatalysis. Green Energy Technol. 2013, 71, 35-66.

32. Réti, B.; Németh, K.; Németh, Z.; Mogyorósi, K.; Markó, K.; Erdohelyi, A.; Dombi, A.; Hernadi, K. Photocatalytic measurements of $\mathrm{TiO}_{2} / \mathrm{MWCNT}$ catalysts having different surface coverage. Phys. Status Solidi Basic Res. 2011, 248, 2475-2479. [CrossRef]

33. Jitianu, A.; Cacciaguerra, T.; Benoit, R.; Delpeux, S.; Béguin, F.; Bonnamy, S. Synthesis and characterization of carbon nanotubes-TiO 2 nanocomposites. Carbon N. Y. 2004, 42, 1147-1151. [CrossRef]

34. Aroutiounian, V.M.; Arakelyan, V.M.; Khachaturyan, E.A.; Shahnazaryan, G.E.; Aleksanyan, M.S.; Forro, L.; Magrez, A.; Hernadi, K.; Nemeth, Z. Manufacturing and investigations of i-butane sensor made of $\mathrm{SnO}_{2}$ /multiwall-carbon-nanotube nanocomposite. Sens. Actuators B Chem. 2012, 173, 890-896. [CrossRef]

35. Khanderi, J.; Contiu, C.; Engstler, J.; Hoffmann, R.C.; Schneider, J.J.; Drochner, A.; Vogel, H. Binary $\left[\mathrm{Cu}_{2} \mathrm{O} / \mathrm{MWCNT}\right]$ and ternary $\left[\mathrm{Cu}_{2} \mathrm{O} / \mathrm{ZnO} / \mathrm{MWCNT}\right]$ nanocomposites: Formation, characterization and catalytic performance in partial ethanol oxidation. Nanoscale 2011, 3, 1102-1112. [CrossRef] 
36. Yu, Y.; Ma, L.L.; Huang, W.Y.; Du, F.P.; Yu, J.C.; Yu, J.G.; Wang, J.B.; Wong, P.K. Sonication assisted deposition of $\mathrm{Cu}_{2} \mathrm{O}$ nanoparticles on multiwall carbon nanotubes with polyol process. Carbon N. Y. 2005, 43, 670-673. [CrossRef]

37. Zhu, L.P.; Liao, G.H.; Huang, W.Y.; Ma, L.L.; Yang, Y.; Yu, Y.; Fu, S.Y. Preparation, characterization and photocatalytic properties of ZnO-coated multi-walled carbon nanotubes. Mater. Sci. Eng. B Solid-State Mater. Adv. Technol. 2009, 163, 194-198. [CrossRef]

38. Jiang, L.; Gao, L. Fabrication and characterization of ZnO-coated multi-walled carbon nanotubes with enhanced photocatalytic activity. Mater. Chem. Phys. 2005, 91, 313-316. [CrossRef]

39. Wang, X.; Xia, B.; Zhu, X.; Chen, J.; Qiu, S.; Li, J. Controlled modification of multiwalled carbon nanotubes with ZnO nanostructures. J. Solid State Chem. 2008, 181, 822-827. [CrossRef]

40. Khayyat, S.A.; Abaker, M.; Umar, A.; Alkattan, M.O.; Alharbi, N.D.; Baskoutas, S. Synthesis and Characterizations of Cd-Doped $\mathrm{ZnO}$ Multipods for Environmental Remediation Application. J. Nanosci. Nanotechnol. 2012, 12, 8453-8458. [CrossRef] [PubMed]

41. Aroutiounian, V.M.; Adamyan, A.Z.; Khachaturyan, E.A.; Adamyan, Z.N.; Hernadi, K.; Pallai, Z.; Nemeth, Z.; Forro, L.; Magrez, A.; Horvath, E. Study of the surface-ruthenated $\mathrm{SnO}_{2} / \mathrm{MWCNTs}$ nanocomposite thick-film gas sensors. Sens. Actuators B. Chem. 2013, 177, 308-315. [CrossRef]

42. Fujishima, A.; Honda, K. Electrochemical photolysis of water at a semiconductor electrode. Nature 1972, 238, 37-38. [CrossRef]

43. Wang, W.; Serp, P.; Kalck, P.; Faria, J.L. Visible light photodegradation of phenol on $\mathrm{MWNT}^{-\mathrm{TiO}_{2}}$ composite catalysts prepared by a modified sol-gel method. J. Mol. Catal. A Chem. 2005, 235, 194-199. [CrossRef]

44. Jiang, Z.Y.; Xie, Z.X.; Zhang, X.H.; Lin, S.C.; Xu, T.; Xie, S.Y.; Huang, R.B.; Zheng, L.S. Synthesis of single-crystalline $\mathrm{ZnO}$ polyhedral submicrometer-sized hollow beads using laser-assisted growth with ethanol droplets as soft templates. Adv. Mater. 2004, 16, 904-907. [CrossRef]

45. Yin, D.; Zhang, L.; Liu, B.; Wu, M. Preparation and Characterization of ZnO-Graphene Composite Photocatalyst. J. Nanosci. Nanotechnol. 2012, 12, 937-942. [CrossRef]

46. Behnajady, M.A.; Modirshahla, N.; Hamzavi, R. Kinetic study on photocatalytic degradation of C.I. Acid Yellow 23 by ZnO photocatalyst. J. Hazard. Mater. 2006, 133, 226-232. [CrossRef]

47. Huang, M.H.; Mao, S.; Feick, H.; Yan, H.; Wu, Y.; Kind, H.; Weber, E.; And, R.R.; Yang, P. Room-Temperature Ultraviolet Nanowire Nanolasers. Science. 2001, 292, 1897-1899. [CrossRef]

48. Barthwal, S.; Singh, N.B. ZnO-CNT Nanocomposite: A Device as Electrochemical Sensor. Mater. Today Proc. 2017, 4, 5552-5560. [CrossRef]

49. Miribangul, A.; Ma, X.; Zeng, C.; Zou, H.; Wu, Y.; Fan, T.; Su, Z. Synthesis of $\mathrm{TiO}_{2} / \mathrm{CNT}$ Composites and its Photocatalytic Activity Toward Sudan (I) Degradation. Photochem. Photobiol. 2016, 92, 523-527. [CrossRef]

50. Trocino, S.; Donato, A.; Latino, M.; Donato, N.; Leonardi, S.G.; Neri, G. Pt-TiO $2 / \mathrm{MWCNTs}_{\text {Hybrid }}$ Composites for Monitoring Low Hydrogen Concentrations in Air. Sensors 2012, 12, 12361-12373. [CrossRef]

51. Lupan, O.; Schütt, F.; Postica, V.; Smazna, D.; Mishra, Y.K.; Adelung, R. Sensing performances of pure and hybridized carbon nanotubes-ZnO nanowire networks: A detailed study. Sci. Rep. 2017, 7, 14715. [CrossRef]

52. Rahman, M.M.; Marwani, H.M.; Algethami, F.K.; Asiri, A.M. Xanthine sensor development based on ZnO-CNT, ZnO-CB, ZnO-GO and ZnO nanoparticles: An electrochemical approach. New J. Chem. 2017, 41, 6262-6271. [CrossRef]

53. Farazmand, P.; Khanlary, M.; Fehli, S.; Salar Elahi, A.; Ghoranneviss, M. Synthesis of Carbon Nanotube and Zinc Oxide (CNT-ZnO) Nanocomposite. J. Inorg. Organomet. Polym. Mater. 2015, 25, 942-947. [CrossRef]

54. Potirak, P.; Pecharapa, W.; Techitdheera, W. Microwave-assisted synthesis of ZnO/MWCNT hybrid nanocomposites and their alcohol-sensing properties. J. Exp. Nanosci. 2014, 9, 96-105. [CrossRef]

55. Abbas, N.; Shao, G.N.; Haider, M.S.; Imran, S.M.; Park, S.S.; Jeon, S.J.; Kim, H.T. Inexpensive sol-gel synthesis of multiwalled carbon nanotube- $\mathrm{TiO}_{2}$ hybrids for high performance antibacterial materials. Mater. Sci. Eng. C 2016, 68, 780-788. [CrossRef]

56. Šćepanović, M.J.; Grujić-Brojčin, M.; Dohčević-Mitrović, Z.D.; Popović, Z.V. Characterization of anatase $\mathrm{TiO}_{2}$ nanopowder by variable-temperature raman spectroscopy. Sci. Sinter. 2009, 41, 67-73. [CrossRef]

57. Xing, Y.J.; Xi, Z.H.; Xue, Z.Q.; Zhang, X.D.; Song, J.H.; Wang, R.M.; Xu, J.; Song, Y.; Zhang, S.L.; Yu, D.P. Optical properties of the $\mathrm{ZnO}$ nanotubes synthesized via vapor phase growth. Appl. Phys. Lett. 2003, 83, 1689-1691. [CrossRef] 
58. Inoue, F.; Ando, R.A.; Corio, P. Raman evidence of the interaction between multiwalled carbon nanotubes and nanostructured $\mathrm{TiO}_{2}$. J. Raman Spectrosc. 2011, 42, 1379-1383. [CrossRef]

59. Miranda, S.M.; Romanos, G.E.; Likodimos, V.; Marques, R.R.N.; Favvas, E.P.; Katsaros, F.K.; Stefanopoulos, K.L.; Vilar, V.J.P.; Faria, J.L.; Falaras, P.; et al. Pore structure, interface properties and photocatalytic efficiency of hydration/dehydration derived $\mathrm{TiO}_{2} / \mathrm{CNT}$ composites. Appl. Catal. B Environ. 2014, 147, 65-81. [CrossRef]

60. Min, Y.; Lee, I.H.; Lee, Y.H.; Hwang, C.S. Botryoidal growth of crystalline ZnO nanoparticles on a forest of single-walled carbon nanotubes by atomic layer deposition. CrystEngComm 2011, 13, 3451. [CrossRef]

61. Srivastava, A.K.; Gakhar, R.; Dua, P.; Senthil, K.; Tawale, J.S.; Sood, K.N.; Yong, K. Structural determination of Zn-O dumbbells in facetted nano-particles. Microscopy 2010, 1, 1820-1823.

62. Piyadasa, A.; Wang, S.; Gao, P.X. Band structure engineering strategies of metal oxide semiconductor nanowires and related nanostructures: A review. Semicond. Sci. Technol. 2017, 32, 073001. [CrossRef]

63. Szabó, A.; Kovács, G.; Kovács, A.; Hernadi, K. Different pathways for synthesis of $\mathrm{WO}_{3}$ and vertically aligned carbon nanotube-based nanostructures. JNN 2019, accepted.

(C) 2019 by the authors. Licensee MDPI, Basel, Switzerland. This article is an open access article distributed under the terms and conditions of the Creative Commons Attribution (CC BY) license (http://creativecommons.org/licenses/by/4.0/). 